\title{
Indigenous youth co-develop a new way to measure their health
}

\author{
n Cite as: CMAJ 2020 March 23;192:E327-8. doi: 10.1503/cmaj.1095854
}

Posted on cmajnews.com on March 6, 2020

$$
\text { chi }
$$

ndigenous communities across Canada are adapting a new way of measuring child and youth well-being with a tool co-designed by Indigenous youth. Those behind the tool say Indigenous-developed health measures are desperately lacking, although vitally important as communities continue to contend with the mental health fallout of colonization.

Called "Aaniish Naa Gegii" (Ojibwe for "How are you?"), the tablet-based tool asks 62 questions across the four aspects of health represented by the Medicine Wheel: physical, mental, emotional and spiritual. Communities use the tool, also known as the Aboriginal Children's Health and Wellbeing Measure (ACHWM), to assess the needs of groups of young people. For example, it's been used to measure the need for more school-based supports to address bullying. It's also been used to evaluate existing programs and to identify individual kids in need of intervention.

Development of the tool started in 2010, when Mary Jo Wabano, health services director for Wiikwemkoong First Nation in northern Ontario, realized that all available measures for evaluating a youth mental health program were designed using a Western lens. "There were no spiritual components to any of the measures," says Wabano. "The mainstream questions didn't resonate with the community."

Wabano approached Dr. Nancy Young, director of the School of Rural and Northern Health at Laurentian University, to partner with the community to create a new measure. When Young presented the questions from other surveys in focus groups with Wikwemikong youth, "they threw almost everything out," she says. "They very much wanted their own voice in this."

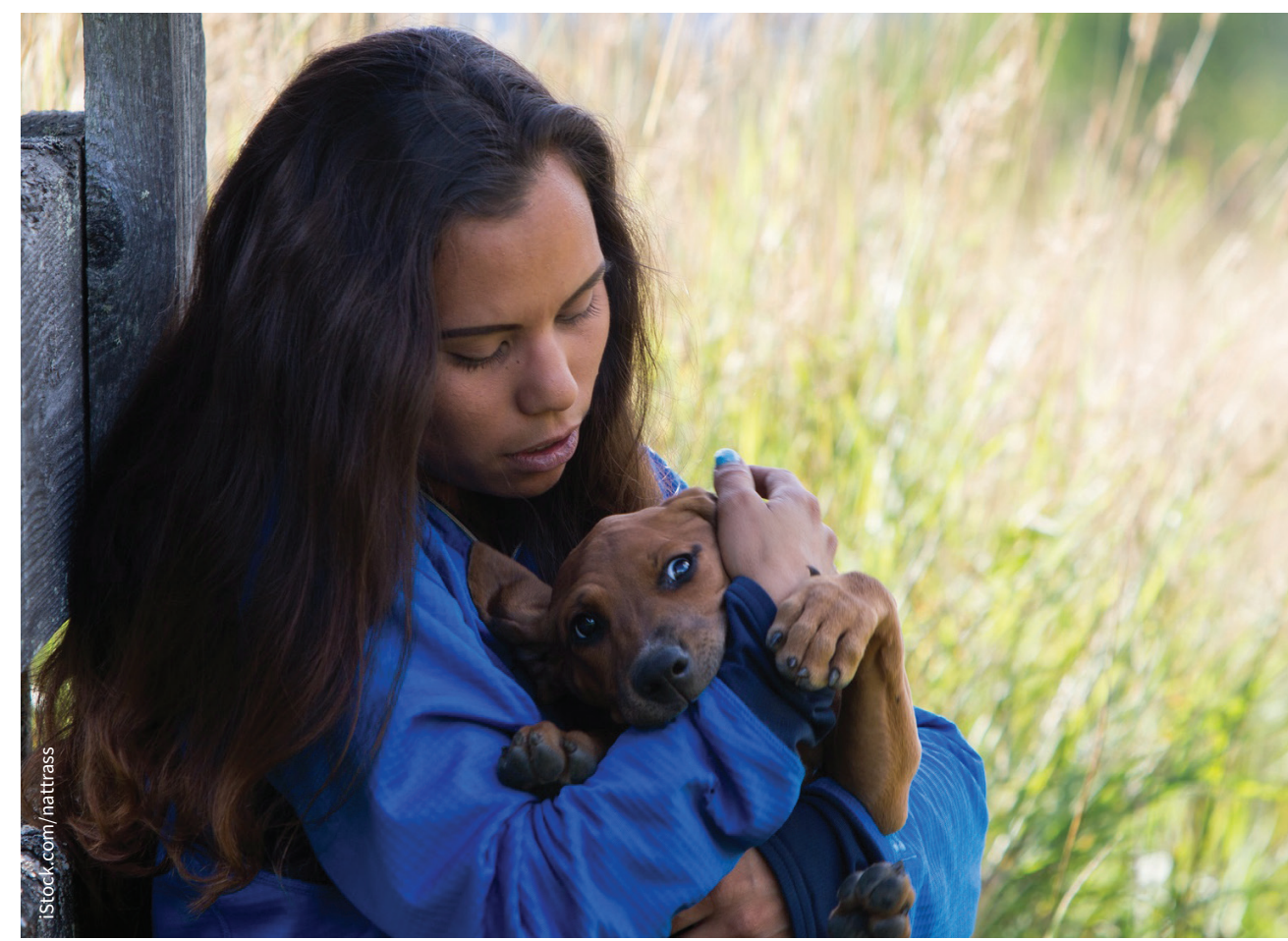

Indigenous children and teens want their realities reflected in the tools that assess their health.

During the development process, children and teens aged eight to 18 placed pictures of items from around the community on the four quadrants of the Medicine Wheel and discussed them. An advisory group, which included health providers, an elder and teachers in the community, used the discussion to create questions for each quadrant. Then, youth in the community assessed the usefulness and clarity of the questions.

Photos of puppies, for example, led to a question asking youth how much they agree with the statement "There's something in my life that makes me happy." Another question asks how much they agree that "There's someone in my life who's there for me." That statement may seem vague, but it's comprehensive enough to capture a range of positive relationships, says Young.

Studies of the tool show it's valid and effective. One study comparing the measure with an in-person assessment by a mental health provider found that $97 \%$ of the time the tool and the provider identified the same children as needing intervention. "The tool doesn't tend to miss," says Young. "Instead, it tends to overcall, so we will send a few extra kids to meet with a worker who are probably fine."

Wabano says it was important to the community that the tool be focused on strengths, because mental health measures can reinforce negative messaging. "We want the focus to be how well we are 
rather than how sick we are, because we are too often being told or shown that we have a deficit," she says.

So far, "the feedback we're hearing is that [the tool] is nonjudgmental, so the children are answering questions freely. And it doesn't take long because you're not sitting down with a piece of paper," Wabano says.

Another rule for the tool's use is that a trained support person must be on site. "We don't want to have a child tell us that they're in trouble and then we let them go," says Young. "That happens to youth over and over again, where they feel people don't listen."

According to Wabano, that support person may be a psychologist or social worker. Initially, only the kids who answered the questionnaire in a way that raised flags saw the support person, but now everyone who completes the survey meets them. "It's another way to introduce the young person to their resources in the community," she says.

The Naandwechige-Gamig Wikwemikong Health Centre and Laurentian University's Evaluating Children's Health Outcomes Research Centre are collaborating with other Indigenous communities to adapt the tool, backed by a $\$ 1.5$ million grant from the Canadian Institutes of Health Research. So far, 50 other communities are at various stages in adapting and using the tool.

Dr. Jennifer Hensel, an assistant professor in psychiatry at the University of Manitoba, conducted a review of digital tools being used for Indigenous mental wellbeing. She says digital tools can "bridge gaps" in remote Indigenous communities, and that the most effective tools are ones that are co-designed with communities. “We didn't come across anything quite like [ACHWM] in that it screens both at an individual and a population level and creates meaningful output for decision makers," she says.

Connecting any technology with onthe-ground, in-person support is key, says Hensel. "Technology is very limited in what it can do, so it's really important to integrate it with a comprehensive program."

Wendy Glauser, Toronto, Ont. 